\title{
Reliability of prenatal diagnosis of genetic diseases by analysis of amplified trophoblast DNA
}

M C Rosatelli, R Sardu, T Tuveri, M T Scalas, A Di Tucci, M De Murtas, G Loudianos, G Monni, A Cao

\begin{abstract}
Dot blot analysis on enzymatically amplified trophoblast DNA with allele specific oligonucleotide probes is currently used for the prenatal diagnosis of single gene disorders characterised at the molecular level, such as the $\beta$ thalassaemias, phenylketonuria, sickle cell anaemia, and $\alpha_{1}$-antitrypsin deficiency. A potential problem with the use of this procedure is the co-amplification of maternal sequences, which may obscure the diagnosis in the fetus. To address this question, we carried out prenatal diagnosis of $\beta$ thalassaemia in 300 couples at risk by dot blot analysis on enzymatically amplified DNA with ${ }^{32} \mathbf{P}$ or horseradish peroxidase labelled allele specific oligonucleotide probes. We verified the diagnosis obtained by this procedure with oligonucleotide hybridisation on electrophoretically separated non-amplified trophoblast DNA fragments. We detected no co-amplified maternal sequences, even with a faint signal, in the dot blot of trophoblast DNA from those fetuses diagnosed as normal or homozygotes, nor in those diagnosed as heterozygotes, who were born to parents carrying different mutations and had inherited the paternal mutation. These results indicate that, when careful dissection of trophoblast tissue from maternal decidua is carried out, amplification of chorionic villi DNA is not associated with amplification of maternal DNA sequences. We may thus conclude that dot blot analysis of trophoblast DNA is a very reliable procedure for prenatal diagnosis.
\end{abstract}

Istituto di Clinica e Biologia dell'Età Evolutiva, Università Studi Cagliari, Via Jenner s/n, 09100 Cagliari, Sardinia, Italy.

M C Rosatelli, R Sardu, T Tuveri, M T Scalas, A Di Tucci, M De Murtas, G Loudianos, A Cao

Servizio di Ostetricia e Ginecologia, Ospedale Regionale per le Microcitemie, USL 21, Cagliari, Sardinia, Italy. G Monni

Correspondence to Professor Cao.

Received for publication 11 August 1989.

Revised version accepted for publication 7 November 1989.
Nowadays a number of mendelian disorders can be detected in fetal trophoblasts by using enzymatically amplified DNA. ${ }^{1-4}$ Those disorders caused by a gross structural rearrangement of the DNA or those affecting a restriction recognition site are directly detected by visualisation with silver nitrate or ethidium bromide staining of the discrete bands resulting from gel electrophoresis of restriction enzyme digested enzymatically amplified DNA. ${ }^{4-6}$ This method is very simple because it circumvents the use of molecular probes. .Disorders produced by point mutations or minimal rearrangements of DNA, such as the deletion or addition of a few nucleotides, are defined by dot blot analysis on amplified DNA with allele specific oligonucleotide probes. ${ }^{78}$ The sensitivity of this procedure allows the use of non-radioactive probes, such as horseradish peroxidase labelled oligonucleotides. ${ }^{9}$ The main advantages of these procedures are the sensitivity (less than $0.05 \mu \mathrm{g}$ of fetal DNA is necessary) and the rapidity (the results can be obtained within 24 hours of sampling). A potential problem, however, may arise from the co-amplification of residual maternal decidua cells which may confuse the diagnosis of the fetus:

In this paper, we report the results of prenatal diagnosis of $\beta$ thalassaemia in 300 pregnancies at risk carried out by dot blot analysis on enzymatically amplified trophoblast DNA with ${ }^{32} \mathbf{P}^{78}$ or horseradish labelled oligonucleotide probes, ${ }^{9}$ and verified by oligonucleotide hybridisation on non-amplified trophoblast DNA fragments separated by gel electrophoresis. $^{10}$

In none of the cases investigated was amplification of maternal sequences found and diagnoses on amplified DNA were confirmed without exception by the analysis of non-amplified DNA. This indicates that analysis of amplified DNA is a reliable procedure for fetal diagnosis of genetic diseases.

\section{Patients and methods}

Three hundred pregnant women of Italian descent requesting prenatal diagnosis because they were at risk for thalassaemia major were included in this study. 
Definition of the $\beta$ thalassaemia mutation in both parents was obtained by dot blot analysis on enzymatically amplified DNA with a series of allele specific oligonucleotide probes complementary to the eight most common mutations in the Mediterranean area. These were the $G \rightarrow A$ substitution at IVS-1 position $110\left(\beta^{+}\right.$IVS-1 nt 110$)$, the codon 39 nonsense mutation $\left(\beta^{\circ} 39\right)$, the $\mathrm{T} \rightarrow \mathrm{C}$ nucleotide substitution at IVS-1 position $6\left(\beta^{+}\right.$IVS -1 nt 6$)$, the $\mathrm{G} \rightarrow \mathrm{A}$ transition at IVS-1 position 1 ( $\beta^{\circ}$ IVS-1 nt $1)$, the $G \rightarrow A$ substitution at IVS -2 position $1\left(\beta^{\circ}\right.$ IVS -2 nt 1 ), the frameshift mutation (GAG $\rightarrow$ GG) at codon $6\left(\beta^{\circ} 6-1 \mathrm{bp}\right)$, the $\mathrm{C} \rightarrow \mathrm{G}$ substitution at position -87 from the CAP site $\left(\beta^{+}-87\right)$, and the $\mathrm{C} \rightarrow \mathrm{G}$ mutation at IVS -2 position $745\left(\beta^{+}\right.$IVS $-2 \mathrm{nt}$ 745). ${ }^{11}$

Chorionic villi sampling was carried out transabdominally from 10 to 14 weeks' gestation. Trophoblast tissue was accurately dissected from maternal decidua under an inverted microscope. Fetal diagnosis was accomplished by dot blot analysis on enzymatically amplified trophoblast DNA with oligonucleotide probe(s) complementary to the mutation(s) detected in the parents. All the diagnoses were verified by oligonucleotide hybridisation on trophoblast DNA restriction fragments separated by agarose gel electrophoresis. DNA amplification, dot blot analysis, and oligonucleotide analysis on electrophoretically separated DNA fragments were carried out as previously described. ${ }^{7} 101213$ The oligonucleotide probes were labelled either with ${ }^{32} \mathrm{P}$ or horseradish peroxidase (a generous gift from Cetus Corporation, CA).

\section{Results}

The $\beta$ globin genotypes of the 300 couples at risk are reported in table 1 .

Out of 300 fetuses investigated, 80 were normal and there were 69 homozygotes, 19 compound hetero-

Table 1 B thalassaemia mutations detected in the couples at risk investigated.

\begin{tabular}{|c|c|c|}
\hline f thalassaemia mutation & No & $\%$ \\
\hline $\begin{array}{l}3^{\circ} 39 / \beta^{\circ} 39 \\
\beta^{\circ} 39 / \beta+\text { IVS-1 nt } 110 \\
\beta^{\circ} 39 / \beta+\text { IVS-1 nt } 6 \\
\beta^{\circ} 39 / \text { others } \\
\beta+\text { IVS-1 nt } 110 / \beta+\text { IVS-1 nt } 110 \\
;+ \text { IVS-1 nt } 110 / \beta+\text { IVS-1 nt } 6 \\
\beta+\text { IVS-1 nt } 110 / \text { others } \\
;+ \text { IVS-1 nt } 6 / \text { others } \\
\beta^{\circ} \text { IVS-2 nt } 1 / \beta^{\circ} \text { IVS-2 nt } 1 \\
\beta^{\circ} \text { IVS-1 nt } 1 / \beta^{\circ} \text { IVS-1 nt } 1 \\
\beta 6[-1 \text { bp]//36 }[-1 \text { bp] } \\
\text { Others* }\end{array}$ & $\begin{array}{r}225 \\
16 \\
8 \\
28 \\
5 \\
4 \\
6 \\
4 \\
1 \\
1 \\
1 \\
1\end{array}$ & 75 \\
\hline Total & 300 & \\
\hline
\end{tabular}

${ }^{*}=\beta 6[-1 \mathrm{bp}], \beta^{\circ}$ IVS $-2 \mathrm{nt} 1, \beta+$ IVS -2 nt $745, \partial \beta$ thal, Hb Lepore, $\mathrm{HbS}$. zygotes, and 132 heterozygotes for $\beta$ thalassaemia (table 2). Figs 1 and 2 show a representative dot blot of the DNA from normal, homozygous, and heterozygous fetuses and their parents. We looked for the presence of co-amplified maternal sequences, even with a faint signal, in the dot blots of trophoblast

Table 2 Overall results of prenatal diagnosis of $\beta$ thalassaemia by dot blot analysis on amplified DNA.

\begin{tabular}{lc}
\hline Pregnancies monitored & 300 \\
Homozygous fetuses* & 88 \\
Heterozygous fetuses & 132 \\
Normal fetuses & 80 \\
Failures & - \\
Misdiagnosest & - \\
\hline
\end{tabular}

${ }^{*}$ Of whom 19 were compound heterozygotes for two different mutations.

†All the diagnoses were confirmed by oligonucleotide analysis on non-amplified DNA.

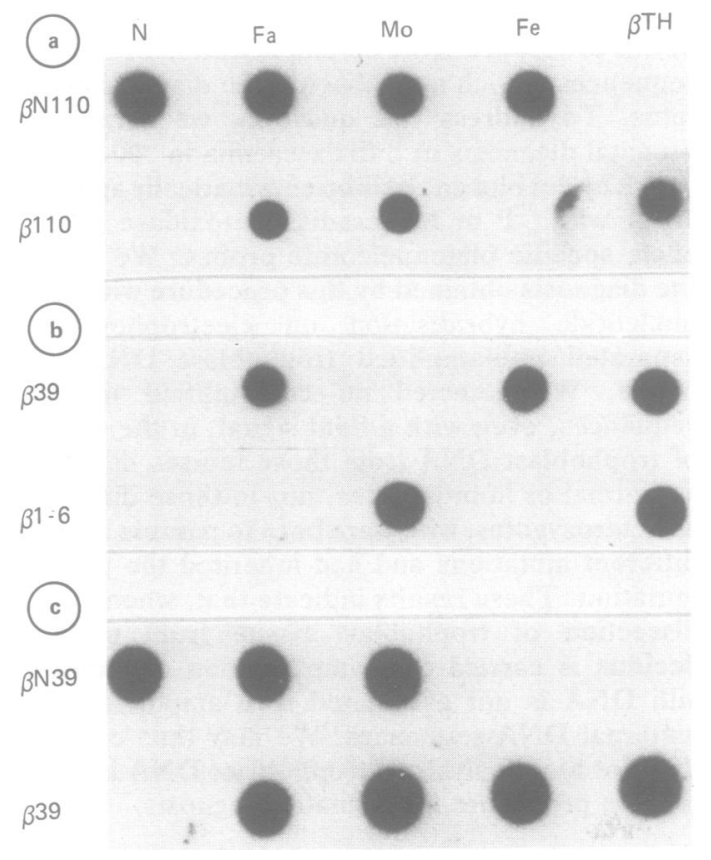

Figure 1 Dot blot analysis on amplified DNA with ${ }^{32} P$ labelled allele specific oligonucleotide probes. $\beta 110, \beta 1-6$, and $\beta 39$ oligonucleotide probes complementary to the $\beta^{+}$IVS-1 nt $110, \beta^{\dagger}$ IVS -1 nt 6 , and $\beta^{\circ} 39$ mutations, respectively. $\beta N 110$ and $\beta N 39=$ oligonucleotide probes complementary to normal DNA sequences at a position corresponding to each of the $\beta$ thal mutations investigated. $N$ and $\beta T H=$ normal and homozygous affected control. $\mathrm{Fa}, \mathrm{Mo}$, and $\mathrm{Fe}=$ indicate father, mother, and fetus. (a) Normal fetus showing no hybridisation to the oligonucleotide probe complementary to the $\beta^{+}$IVS-1 nt 110 mutation. (b) Heterozygous fetus showing no hybridisation to the oligonucleotide probe complementary to the mother's mutation $(\beta I-6)$. (c) Homozygous affected fetus showing no hybridisation to the oligonucleotide probe complementary to normal DNA sequences corresponding to the $\beta^{\circ} 39$ mutation. 

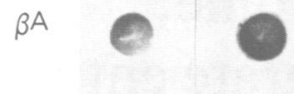

$\beta \mathrm{TH}$

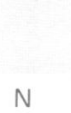

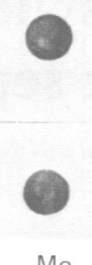

$\mathrm{Fa}$
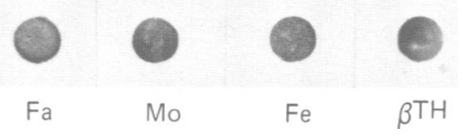

Figure 2 Dot blot analysis on amplified DNA with horseradish peroxidase labelled oligonucleotide probes. $\beta N$ and $\beta T H=$ oligonucleotide probes complementary to normal and mutated $\left(\beta^{39}\right) D N A$ sequences respectively. $F a, M o, F e=$ indicate father, mother, and fetus. Homozygous affected fetus showing no hybridisation to an oligonucleotide probe complementary to normal DNA sequences corresponding to the mutation.

DNA from fetuses diagnosed as normal or homozygous, as well as those diagnosed as heterozygous who were born to parents carrying different mutations and who had inherited the paternal allele. In the normal fetuses, we did not ever detect a positive hybridisation to an oligonucleotide probe complementary to the mutation detected in the mother. Similarly, in the homozygous fetuses, hybridisation to oligonucleotide probes complementary to the normal sequences at the position corresponding to the mutation detected in the mother was never observed.

In 19 heterozygous fetuses who were born to parents carrying different mutations and who had inherited the paternal mutation, we never observed a positive hybridisation to an oligonucleotide probe complementary to the maternal mutation.

In all cases tested, diagnosis obtained by dot blot analysis on amplified DNA was confirmed by oligonucleotide hybridisation on non-amplified DNA.

Out of 300 fetuses examined, 68 went to term and diagnosis was confirmed by DNA analysis.

\section{Discussion}

This paper, based on a large number of cases, indicates that prenatal diagnosis of $\beta$ thalassaemia by dot blot analysis on enzymatically amplified DNA with allelic specific oligonucleotide probes is a very reliable diagnostic procedure. We did not detect any co-amplified maternal sequences, even with a faint signal, in the dot blot of trophoblast DNA from those fetuses diagnosed as normal or homozygous, or those diagnosed as heterozygous who were born to parents carrying different mutations and who had inherited the paternal mutation.

Furthermore, the results obtained on amplified DNA were confirmed, without exception, by the analysis of non-amplified DNA. We can therefore conclude that the potential problems in prenatal diagnosis using amplification of maternal sequences do not occur when careful dissection of trophoblast tissue from maternal decidua is carried out. Since this study was completed, we have introduced this procedure for routine use in the laboratory of our unit for prenatal diagnosis of genetic diseases. The results obtained in this study are obviously also relevant to other single gene disorders characterised at the molecular level, such as $\alpha_{1}$-antitrypsin deficiency, cystic fibrosis, and phenylketonuria which could be diagnosed in the fetus by dot blot analysis on amplified DNA.

The authors wish to thank Mrs Sally Harvey and Rita Loi for editorial assistance. Support for this study was provided by a grant from Assessorato Igiene e Sanità Regione Sardegna (progetto ricerca sanitaria finalizzata: 'Malattie Genetiche di notevole rilevanza in Sardegna'), MPI 40 and 60\% (A Cao, C Rosatelli).

1 Abbott CM, McMahon CJ, Whitehouse DB, Povey S. Prenatal diagnosis of alpha-1-antitrypsin deficiency using polymerase chain reaction. Lancet $1988 ; \mathrm{i}: 763-4$.

2 Feldman GL, Williamson R, Beaudet AL, O'Brien WE. Prenatal diagnosis of cystic fibrosis by DNA amplification for detection of KM-19 polymorphism. Lancet 1988;ii: 102 .

3 Kogan SC, Doherty M, Gitschier J. An improved method for prenatal diagnosis of genetic diseases by analysis of amplified DNA sequences. Application to hemophilia A. N Engl $\mathcal{7}$ Med 1987;317:985-90.

4 Chehab FF, Doherty M, Cai S, Kan YW, Cooper S, Rubin EM Detection of sickle cell anaemia and thalassaemias. Nature 1987;329:293-4.

5 Chehab FF, Cai SP, Doherty M, Kan YW, Cooper S, Rubin EM Simple and rapid nonradioactive DNA analysis for the prenatal diagnosis of sickle cell anemia and homozygous $(\ell$-thalassemia. Am f Hum Genet 1987;41 (suppl 3):269A.

6 Chan V, Chan TK, Kan YW, Todd D. A novel beta-thalassemia frameshift mutation (codon 14/15), detectable by direct visualization of abnormal restriction fragment in amplified genomic DNA. Blood 1988;72:1420-3.

7 Saiki RK, Bugawan TL, Horn GT, Mullis KB, Erlich HA. Analysis of enzymatically amplified $\beta$-globin and HLA-DQ DNA with allele-specific oligonucleotide probes. Nature 1986; 324: $163-6$.

8 Cai SP, Zhang JZ, Huang DH, Wang ZX, Kan YW. A simple approach to prenatal diagnosis of beta-thalassemia in a geographic area where multiple mutations occur. Blood 1988: 71:1357-60.

9 Saiki RK, Chang CA, Levenson CH, et al. Diagnosis of sickle cell anemia and beta-thalassemia with enzymatically amplified DNA and nonradioactive allele specific oligonucleotide probes. N Engl 7 Med 1988;319:537-41.

10 Rosatelli C, Falchi AM, Tuveri T, et al. Prenatal diagnosis of beta-thalassaemia with the synthetic-oligomer technique. Lancel $1985 ; \mathbf{i}: 241-3$.

11 Kazazian HH Jr, Boehm CD. Molecular basis and prenatal diagnosis of $\beta$-thalassemia. Blood 1988;72:1107-16.

12 Pirastu M, Kan YW, Cao A, Conner BJ, Teplit\% RL, Wallace RB. Prenatal diagnosis of $\beta$-thalassemia. Detection of a single nucleotide mutation on DNA. $N$ Engl f Med 1983;309:284-7.

13 Ristaldi MS, Pirastu M, Rosatelli C, et al. Prenatal diagnosis of pthalassaemia in Mediterranean populations by dot blot analysis with DNA amplification and allele specific oligonucleotide probes. Prenat Diagn 1989;9:629-38. 